\title{
Minireview \\ Second primary breast cancer after Hodgkin's disease
}

\author{
A Horwich ${ }^{*, 1}$ and AJ Swerdlow ${ }^{2}$ \\ 'Academic Unit of Radiotherapy and Oncology, The Royal Marsden NHS Trust and the Institute of Cancer Research, Downs Road, Sutton, Surrey SM2 \\ 5NG, UK; ${ }^{2}$ Aetiological Epidemiology, The Royal Marsden NHS Trust and the Institute of Cancer Research, Downs Road, Sutton, Surrey SM2 5NG, UK
}

\begin{abstract}
Although the potential carcinogenic risk of radiotherapy is well known, it has become clear that there is a particularly high risk of radiation-induced breast cancer in women treated for Hodgkin's disease at young ages. Thankfully, death from breast cancer in this population is uncommon, but it is important to understand factors contributing to the risk, including treatment parameters, and to develop a logical and efficient method for medical management of those at risk. In this minireview, we examine the evidence which should inform such a management policy.

British Journal of Cancer (2004) 90, 294-298. doi:I0.I038/sj.bjc.660I499 www.bjcancer.com

(c) 2004 Cancer Research UK
\end{abstract}

The prognosis of patients with Hodgkin's disease has been improved dramatically over the last 40 years by the development of extended field radiotherapy techniques and then by combination chemotherapy (DeVita et al, 1980; Rosenberg and Kaplan, 1985). However, long-term follow-up of survivors has demonstrated that a price of this success has been an increased risk of second cancers. Acute leukaemia frequently occurs in the first decade after treatment, mainly as a consequence of chemotherapy regimens that included an alkylating agent (Tucker et al, 1988; Kaldor et al, 1990; Swerdlow et al, 2000). In the long term, however, the absolute excess risks of a second solid cancer are higher (Swerdlow et al, 2000; Ng et al, 2002b; van Leeuwen et al, 2003) and are linked mainly with radiotherapy, although for some sites, such as lung cancer, there may be a substantial risk also from chemotherapy (Swerdlow et al, 2000; Travis et al, 2002). Recent reports from The Netherlands (van Leeuwen et al, 2003) and from an international consortium of cancer registries (Travis et al, 2003) have refined our understanding of how therapy may affect breast cancer risk.

The relative risks of many cancers are higher if patients have been treated for Hodgkin's disease at a younger age (Swerdlow et al, 2000; van Leeuwen et al, 2000; Dores et al, 2002). Thus, although the risk of breast cancer is only about $50 \%$ increased in most all-age studies of women with Hodgkin's disease (van Leeuwen et al, 1999), relative risks are far larger than this in patients treated at young ages, especially those treated in childhood and adolescence (Hancock et al, 1993; Bhatia et al, 1996b); for them this is one of the main long-term sequelae of radiotherapy. This effect of age is unsurprising, as similar gradients are seen in other cohorts of radiation-exposed women (United Nations Scientific Committee on the Effects of Atomic Radiation, 1994).

The size of risk of breast cancer found in Hodgkin's disease patients has varied between studies. For patients treated under age 21 years relative risks have generally been around 15-25 (Hancock et al, 1993; Sankila et al, 1996; Wolden et al, 1998; Metayer et al, 2000; van Leeuwen et al, 2000; Dores et al, 2002), although they

*Correspondence: Professor A Horwich; E-mail: alan.horwich@icr.ac.uk Received 17 July 2003; revised 15 October 2003; accepted 27 October 2003 have been less raised (Neglia et al, 2001) or more raised (Mauch et al, 1996; Bhatia et al, 1996b; Aisenberg et al, 1997; Ng et al, $2002 \mathrm{~b})$ than this in a few studies; absolute excess risks have generally been of the order of 20-40 per 10000 per annum. Relative risks have been greater for patients treated at ages 10-16 than at younger or older ages (Hancock et al, 1993; Sankila et al, 1996; Bhatia et al, 1996b; Metayer et al, 2000). Differences between study results partly reflect differences in distributions of age at treatment, radiation dosage and duration of follow-up, but also caution must be exercised in interpretation of studies such as that by Bhatia (Bhatia et al, 1996b), where follow-up to a fixed end-date is incomplete. Such incompleteness will tend to be predominantly for subjects who have not had a second malignancy and hence will artefactually increase apparent risks in relation to years of successful follow-up (Donaldson and Hancock, 1996). Similarly, estimates of cumulative risk of breast cancer after treatment at young ages have at the extreme been estimated at $42 \%$ at 30 years of follow-up for women treated under age 16 years in a study with incomplete follow-up (Bhatia et al, 1996a), but studies with highquality follow-up have found cumulative risks of $12 \%$ at 30 years after treatment in the Nordic countries (Sankila et al, 1996) and $16 \%$ at 25 years in the Netherlands (van Leeuwen et al, 2000) for patients treated under age 21 years. In median 18-year follow-up of over 500 women treated at ages under 41 years in the Dutch cohort, only five deaths occurred from breast cancer (Aleman et al, 2003), and among 161 deaths in long-term follow-up of 494 women treated under age 51 years in the US, four were from breast cancer ( $\mathrm{Ng}$ et al, 2002a)

Risks of second primary breast cancer are also raised after treatment for Hodgkin's disease in young adulthood, although relative risks are lower than those for childhood and adolescent treatment (Hancock et al, 1993; van Leeuwen et al, 2000; $\mathrm{Ng}$ et al, $2002 \mathrm{~b}$ ), reflecting the greater background rates at older ages. However, a lesser relative risk does not necessarily imply a lesser absolute excess, and indeed van Leeuwen et al (2000) in the Netherlands and Hancock et al (1993)and Ng et al (2002b) in the US found absolute excess risks fairly similar for patients treated at ages 20-29 years to those for patients treated under age 20 years. For treatment at ages 30 years and above, most studies have found no raised risk (Hancock et al, 1993; Aisenberg et al, 1997; Swerdlow et al, 2000), although in a large Dutch cohort there was a relative risk of $2.4(0.9-5.2)$ for patients treated at ages 31-39 
years (van Leeuwen et al, 2000) and in a US cohort there were relative risks of $3.7(1.0-9.5)$ for women treated at 30-35 years and $3.4(0.4-12.1)$ for those treated at $36-40$ years) ( $\mathrm{Ng}$ et al, 2002b) It thus seems possible that the raised risks extend a little beyond age 30 years, but it is unclear how far.

The cause of the raised risk of breast cancer patients treated for Hodgkin's disease is exposure to radiotherapy fields that involve the breast. Most of the data discussed above, however, relate to women treated for Hodgkin's disease overall, and thus risks are greater if only patients exposed to radiotherapy are considered. For instance, in a UK cohort (Swerdlow et al, 2000) the relative risk of breast cancer for women treated under age 25 years was 7.7, but for those treated by radiotherapy alone at these ages it was 14.4.

In adults, at least, the induction period before breast cancer is observed is long, with significantly raised risks appearing only at 10-14 (Swerdlow et al, 2000; Dores et al, 2002; Ng et al, 2002b) or 15-19 (Hancock et al, 1993; van Leeuwen et al, 2000) years after first treatment. After childhood or adolescent treatment, however, induction periods appear to be shorter (Bhatia et al, 1996b; Sankila et al, 1996; Travis et al, 1996; Metayer et al, 2000), indeed as short as within the first 5 years in one study (Bhatia et al, 1996b).

As a consequence of the long induction periods in adults, the great majority of breast cancers after Hodgkin's disease radiotherapy occur after age 30 years. How long the risks remain raised is as yet unknown, because of the limited length of follow-up yet available in published studies. Several groups have presented data for 20 and more years of follow-up, finding large and significant relative risks of breast cancer for this time period (Hancock et al, 1993; Bhatia et al, 1996b; Wolden et al, 1998; Metayer et al, 2000; van Leeuwen et al, 2000). One study has published cohort results for 25 and more years, again with a significantly raised risk (Dores et al, 2002) (in a case-control study with no general population comparison, the risk was nonsignificantly raised at 25 and more years for radiation-exposed women (Travis et al, 2003)). Relative risks in these studies have usually been somewhat diminished in the longest follow-up period compared with the period preceding it, whereas absolute excess risks, when these have been published, have been at least as great as in the preceding period (Hancock et al, 1993; Wolden et al, 1998; van Leeuwen et al, 2000). Although one cannot be sure what will occur at yet longer follow-up periods, judging from other radiation exposed groups it would be expected that there would be substantial raised risks persisting through 40 or more years of follow-up (Committee on the Biological Effects of Ionizing Radiation (BEIR), 1990).

Breast cancers occurring after treatment for Hodgkin's disease are more likely to be bilateral than breast cancers in general (Yahalom et al, 1992; Basu et al, 2002). There is little information on the molecular phenotype of breast cancers after Hodgkin's disease; in one study 10 out of 18 tumours examined were oestrogen receptor negative (Yahalom et al, 1992). A study of 19 tumours found no apparent difference between post-Hodgkin's and sporadic breast cancers in loss of heterozygosity or in TP53 and K-ras mutations, and a nonsignificantly raised frequency of micosatellite alterations in the post-Hodgkin's disease tumours (Behrens et al, 2000). Two studies have described raised risk of breast cancer in Hodgkin's disease patients who have undergone splenectomy or splenic irradiation (Dietrich et al, 1994; Bhatia et al, 1996b), but there are insufficient data to regard this as an established association. Based on limited data, no clear relation has been found with reproductive history (Travis et al, 2003).

It would be of great interest to know whether radiotherapyrelated risks interact with those from genes affecting breast cancer susceptibility, but there is almost no information on this. Bhatia et al (1997) found no excess of breast cancer in relatives of patients with breast cancer after Hodgkin's disease, but this was based on small numbers. Because carriers of the ataxia telangiectasia (AT) gene have increased in vitro sensitivity to radiation, and have been found to have raised risk of breast cancer (Ramsey et al, 1996), they might be a group for whom radiotherapy constitutes a particular hazard. Genetic analyses of 32 patients developing breast cancer more than 10 years after radiotherapy for Hodgkin's disease did not reveal evidence of truncating mutations (Broeks et al, 2000). In a study based on AT gene sequencing which compared HD patients with or without second breast cancers, risk of breast cancer was not associated with either protein-truncating or with excess missense mutations (Offit et al, 2002).

Because much of our knowledge of risk of breast cancer after Hodgkin's disease is derived from treatments carried out in the $1960-1980$ s, there is relatively little information about the likely impact of more recent radiotherapy practices, such as involved field radiotherapy and reduced-dose radiation. Involved field radiation is often employed following chemotherapy in early stage Hodgkin's disease and is confined to overtly involved lymph nodes plus a margin along the node chain. Clearly for presentations confined to cervical lymph glands, breast irradiation would be minimal, and in practice the major component of breast irradiation derives from treating the axilla, which is a relatively uncommon site for early Hodgkin's disease. However, mediastinal involvement is not uncommon and fields to the central chest will necessarily irradiate medial breast segments. A nested casecontrol study from the Netherlands (van Leeuwen et al, 2003) included an estimate from radiotherapy charts as well as dosimetric measurements and planning computer simulations of radiation doses to the local area of the breast where the tumour had developed. The risk of breast cancer increased highly significantly with increasing radiation dose $(P$ trend $=0.002)$, with a relative risk of $4.5(1.3-16)$ for $\geqslant 38.5$ Gy compared with $<4 \mathrm{~Gy}$. This was also shown in the international case-control study (Travis et al, 2003) ( $P$ trend $<0.001$ ), which found a RR of 8 in those treated to a dose of more than $40 \mathrm{~Gy}$ to the breast, compared with less than $4 \mathrm{~Gy}$. The few other studies that have investigated the relation of risk to dosage have not calculated doses specifically to the part of the breast in which the cancer occurred. Two studies found evidence of a dose-response relation (Bhatia et al, 1996b; Tinger et al, 1997) while one did not (Hancock et al, 1993), although the great majority of person-years in the latter study were in one dose category. There are inaccuracies in retrospective dose allocations in such studies because radiotherapy causes breast shrinkage, leading to changes in breast shape of treated women over time. Nevertheless, the data from van Leeuwen's study are strong, and they accord with what one might expect from other epidemiology, so it appears likely that reduction in dosage will reduce the risk of breast cancer.

Chemotherapy alone does not appear to be associated with an increased risk of breast cancer after Hodgkin's disease (Swerdlow et al, 2000; van Leeuwen et al, 2000; Dores et al, 2002), and indeed the available data would be compatible with a reduced risk. Analyses of patients treated with both chemotherapy and radiotherapy have in several studies (Gervais-Fagnou et al, 1999; Swerdlow et al, 2000; van Leeuwen et al, 2000, 2003; Travis et al, 2003) but not all (Hancock et al, 1993; Aisenberg et al, 1997) suggested a reduced risk compared with that after radiotherapy alone. In the British cohort, the relative risk for patients treated at less than 25 years of age was 14.4 after radiotherapy alone and 4.6 after radiotherapy plus chemotherapy (Swerdlow et al, 2000). In the Dutch cohort a similar reduction was seen for patients receiving mixed therapy (van Leeuwen et al, 2003), and indeed the effect of radiation dose on breast cancer risk was only seen in patients who had not received chemotherapy. The diminished risk after chemotherapy was not due to radiation dose reductions in these patients (van Leeuwen et al, 2003). Although the diminished risk could in principle be due to a direct effect on initiated breast epithelial cells, it seems most likely that it is due to ovarian toxicity and consequent hormonal ablation. A nested case-control study from the Netherlands (van Leeuwen et al, 2003) found strong evidence favouring hormonal ablation: 48 case patients who 
developed breast cancer 5 or more years after treatment for Hodgkin's disease were compared with 175 matched controls in whom breast cancer had not occurred. In total, $69 \%$ of controls who had been treated with more than six cycles of chemotherapy plus radiotherapy reached the menopause before the age of 41 years $v s$ only $9 \%$ of controls treated with radiotherapy alone. Reaching menopause before age 36 years was associated with a greatly reduced risk of breast cancer (RR $0.06,95 \%$ CI $0.01-0.45$ ) and risk increased steeply with number of premenopausal years after treatment: relative risks were $0.15,0.24$ and 0.91 for $<5,5-$ 14 , and $\geqslant 15$ premenopausal years, respectively. Travis et al (2003) found that breast cancer risk decreased significantly $(P=0.003)$ with increasing number of alkylating agent cycles and decreased, although the trend was not significant, with younger age at menopause. Thus ovarian hormones may be critical to carcinogenesis after radiation initiation. Such an effect would give a potential explanation of why breast cancer risk decreases with older age at irradiation, as there will be fewer or no years before menopause in patients who are older at radiotherapy. It is notable that after radiotherapy to the ovaries for either HD (Travis et al, 2003) or other conditions (Boice et al, 1985; Darby et al, 1994)., there is also a reduction in risk of breast cancer, presumably mainly due to ovarian failure, although some risk reduction has been found even at postmenopausal ages (Boice et al, 1985; Darby et al, 1994). For Hodgkin's disease, the relation to chemotherapyinduced menopause needs further investigation. Analyses of risk in patients treated in the more recent past with chemotherapy combinations that do not cause ovarian failure, such as adriamycin, bleomycin, vinblastine and dacarbazine (ABVD) (Santoro et al, 1982), may help to clarify this issue.

What should be the clinical response to this risk, given the admittedly incomplete data available? Breast cancer is a common disease with more than 39000 cases per year diagnosed in the UK; the incidence is 45 per 100000 women per annum for women aged in their 30s rising to 300 per 100000 in those in their 80s. Thus, even a modest increase in relative risk is of considerable concern. Issues to consider include advising and counselling patients at risk, the possible benefit of screening or prevention programmes, the impact on current treatment practices for Hodgkin's disease, and the research needed to enable judgement and minimisation of risk in the future. In the UK, the Department of Health is taking steps to ensure appropriate counselling of women at risk. From existing databases, we estimate that there are approximately 2600 women alive and at risk in Britain, although many of these may already have been informed about their risk by physicians in their follow-up clinics. It is important that the risk level be explained in a readily comprehensible way and for most patients this might be in terms of the expected excess number of breast cancers for every 100 years of follow-up as judged from individual risk factors. More detailed risk data than currently available are needed, however, specified by duration of follow-up, age at treatment, and dose, to enable fully personalised advice.

There is evidence that regular mammographic screening may reduce breast cancer mortality. However, this is derived from screening predominantly women more than 50 years of age. In younger women X-ray mammography may be less sensitive because many have increased density of breast tissue, although there is growing evidence that there is some beneficial effect (Tabar et al, 2003). Magnetic resonance imaging is being evaluated to screen younger women and evidence to date suggests that it is a sensitive technique but there may be a higher false-positive rate (Warren and Crawley, 2002). X-ray mammography involves less than 1/1000th of the radiation dose used in treatment of Hodgkin's disease and can be considered for most women at increased risk. In a US study in which Hodgkin's disease patients underwent mammography annually (or every second year before age 30 years), all 12 breast cancers occurring during follow-up were evident on mammogram (Diller et al, 2002) and in another, retrospective study, 26 out of 29 cancers were demonstrated on mammography (Dershaw et al, 1992). Because screening needs to start earlier than clinical cancer risk is raised if it is to serve the purpose of early detection, it would seem reasonable that for women who were given radiotherapy at ages $20-30$ years screening should begin at about 8-10 years postradiotherapy. For women treated before age 20 years, it may be reasonable to add that screening should not start before a fixed attained age - say about 25 years - because of the rarity of second primary breast cancers before ages in the late 20s (Aisenberg et al, 1997). As to frequency of screening, it may be reasonable to follow the procedure for women at high genetic risk of breast cancer, and (in the UK) to recommend annual screening up to age 50 years when the national programme begins, and then to add an additional screening between the three yearly national programme appointments in the light of higher risk and desirability to limit the rate of interval cancers.

With regard to continued use of hormone replacement therapy (HRT) in patients with premature menopause, or hormone-based chemopreventative strategies such as Tamoxifen for those at risk, there are insufficient data to give clear advice. In the study by van Leeuwen (van Leeuwen et al, 2003), risk was not significantly increased in users of HRT, but the number of cases who had used HRT for more than a few years was small and the confidence interval was wide. The information on the possible protective effect of chemotherapy discussed above suggests that hormone ablation may reduce cancer risk, but against this must be weighed the health benefits of HRT, for example in combating osteoporosis. There is a case to consider a chemoprevention trial in patients at risk of breast cancer, although patient willingness to enter such a trial would need to be evaluated carefully to ensure there were sufficient numbers to demonstrate whether there is an effect.

With regard to treatment of future patients, there is a need to take account of the breast cancer risks that would arise from radiotherapy, but to note that these apply only to a subset of all Hodgkin's disease patients (young women), not to all, and that a balanced view of all the benefits and potential long-term adverse effects needs to be taken when selecting treatment. There is a trend in current treatment of Hodgkin's disease toward reduced use of radiotherapy. This comes from lack of clear evidence for overall survival benefit in advanced and disseminated disease presentations (Specht et al, 1998). In early disease, combined modality protocols are used in which chemotherapy is followed by involved field radiation and doses of radiotherapy are reduced (e.g. Sieber et al, 2000). There are limited data on chemotherapy alone in early Hodgkin's disease, and it is uncertain whether disease control rates are as high as with radiotherapy or combined modality approaches (Biti et al, 1992). A current Canadian trial is investigating ABVD in this role. Furthermore, the advent of more sensitive response evaluation based on positron emission tomography (Spaepen et al, 2001) may allow judgement of which patients with early Hodgkin's disease may completely avoid radiotherapy after initial response to chemotherapy.

For those women who do require supradiaphragmatic radiotherapy at ages less than 30 years, it is important to seek to minimise dose and limit volume of breast tissue in the field and to ensure that they are informed of, and accept, the associated risk of second primary breast cancer.

\section{ACKNOWLEDGEMENTS}

This work was undertaken in The Royal Marsden NHS Trust who received a proportion of its funding from the NHS Executive; the views expressed in this publication are those of the authors and not necessarily those of the NHS Executive. This work was supported by the Institute of Cancer Research, the Bob Champion Cancer Trust and Cancer Research UK Section of Radiotherapy. 


\section{REFERENCES}

Aisenberg AC, Finkelstein DM, Doppke KP, Koerner FC, Boivin J-F, Willett CG (1997) High risk of breast carcinoma after irradiation of young women with Hodgkin's disease. Cancer 79: 1203-1210

Aleman BMP, van den Belt-Dusebout AW, Klokman WJ, van't Veer MB, Bartelink H, van Leeuwen FE (2003) Long-term cause-specific mortality of patients treated for Hodgkin's disease. J Clin Oncol 21: $3431-3439$

Basu S, Constine LS, Tarbell N, Hudson M, Schwartz C, Fisher SG, Muhs AG, Biswas T, Kun L, Mendenhall N, Mauch P (2002) Bilateral breast cancer is common in females surviving pediatric Hodgkin's disease. Proc ASCO

Behrens C, Travis LB, Wistuba II, Davis S, Maitra A, Clarke EA, Lynch CF, Glimelius B, Wiklund T, Tarone R, Gazdar AF (2000) Molecular changes in second primary lung and breast cancers after therapy for Hodgkin's disease. Cancer Epidemiol Biomarkers Prev 9: 1027-1035

Bhatia S, Meadows AT, Robison LL, Late Effects Study Group (1997) Family history of patients with breast cancer after treatment of Hodgkin's disease in childhood. Lancet 350: 888-889

Bhatia S, Robison LL, Meadows AT (1996a) Late effects of treatment for childhood Hodgkin's disease. N Engl J Med 335: $353-354$

Bhatia S, Robison LL, Oberlin O, Greenberg M, Bunin G, Fossati-Bellani F, Meadows AT (1996b) Breast cancer and other second neoplasms after childhood Hodgkin's disease. $N$ Engl J Med 334: 745-751

Biti GP, Cimino G, Cartoni C, Magrini SM, Anselmo AP, Enrici RM, Bellesi GP, Bosi A, Papa G, Giannarelli D (1992) Extended-field radiotherapy is superior to MOPP chemotherapy for the treatment of pathologic stage IIIA Hodgkin's disease: eight-year update of an Italian prospective randomized study. J Clin Oncol 10: 378-382

Boice Jr JD, Day NE, Andersen A, Brinton LA, Brown R, Choi NW, Clarke EA, Coleman MP, Curtis RE, Flannery JT (1985) Second cancers following radiation treatment for cervical cancer. An international collaboration among cancer registries. J Natl Cancer Inst 74: 955-975

Broeks A, Russell NS, Floore AN, Urbanus JH, Dahler EC, van T.Veer MB, Hagenbeek A, Noordijk EM, Crommelin MA, van Leeuwen FE (2000) Increased risk of breast cancer following irradiation for Hodgkin's disease is not a result of ATM germline mutations. Int J Radiat Biol 76: $693-698$

Committee on the Biological Effects of Ionizing Radiation (BEIR) (1990) Health Effects of Exposure to Low Levels of Ionizing Radiation: BEIR V. National Academy Press. Washington, DC

Darby SC, Reeves G, Key T, Doll R, Stovall M (1994) Mortality in a cohort of women given X-ray therapy for metropathia haemorrhagica. Int J Cancer 56: $793-801$

Dershaw DD, Yahalom J, Petrek JA (1992) Breast carcinoma in women previously treated for Hodgkin disease: mammographic evaluation. Radiology 184: 421 - 423

DeVita Jr VT, Simon RM, Hubbard SM, Young RC, Berard CW, Moxley JH, III, Frei E, III, Carbone PP, Canellos GP (1980) Curability of advanced Hodgkin's disease with chemotherapy. Long-term follow-up of MOPPtreated patients at the National Cancer Institute. Ann Intern Med 92: $587-595$

Dietrich PY, Henry-Amar M, Cosset JM, Bodis S, Bosq J, Hayat M (1994) Second primary cancers in patients continuously disease-free from Hodgkin's disease: a protective role for the spleen? Blood 84: 1209-1215

Diller L, Medeiros Nancarrow C, Shaffer K, Matulonis U, Mauch P, Neuberg D, Tarbell NJ, Litman H, Garber J (2002) Breast cancer screening in women previously treated for Hodgkin's disease: a prospective cohort study. J Clin Oncol 20: 2085-2091

Donaldson SS, Hancock SL (1996) Second cancers after Hodgkin's disease in childhood. $N$ Engl J Med 334: $792-794$

Dores GM, Metayer C, Curtis RE, Lynch CF, Clarke EA, Glimelius B, Storm $\mathrm{H}$, Pukkala E, van Leeuwen FE, Holowaty EJ, Andersson M, Wiklund T, Joensuu T, van't Veer MB, Stovall M, Gospodarowicz M, Travis LB (2002) Second malignant neoplasms among long-term survivors of Hodgkin's disease: a population-based evaluation over 25 years. J Clin Oncol 20: $3484-3494$

Gervais-Fagnou DD, Girouard C, Laperriere N, Pintillie M, Goss PE (1999) Breast cancer in women following supradiaphragmatic irradiation for Hodgkin's disease. Oncology 57: 224-231

Hancock SL, Tucker MA, Hoppe RT (1993) Breast cancer after treatment of Hodgkin's disease. I Natl Cancer Inst 85: 25-31

Kaldor JM, Day NE, Clarke EA, van Leeuwen FE, Henry-Amar M, Fiorentino MV, Bell J, Pedersen D, Band P, Assouline D (1990) Leukemia following Hodgkin's disease. $N$ Engl J Med 322: 7-13
Mauch PM, Kalish LA, Marcus KC, Coleman CN, Shulman LN, Krill E, Come S, Silver B, Canellos GP, Tarbell NJ (1996) Second malignancies after treatment for laparotomy staged IA - IIIB Hodgkin's disease: longterm analysis of risk factors and outcome. Blood 87: 3625-3632

Metayer C, Lynch CF, Clarke EA, Glimelius B, Storm H, Pukkala E, Joensuu T, van Leeuwen FE, van't Veer MB, Curtis RE, Holowaty E, Andersson M, Wiklund T, Gospodarowicz M, Travis LB (2000) Second cancers among long-term survivors of Hodgkin's disease diagnosed in childhood and adolescence. J Clin Oncol 18: 2435-2443

Neglia JP, Friedman DL, Yasui Y, Mertens AC, Hammond S, Stovall M, Donaldson SS, Meadows AT, Robison LL (2001) Second malignant neoplasms in five-year survivors of childhood cancer: childhood cancer survivor study. J Natl Cancer Inst 93: 618-629

Ng AK, Bernardo MP, Weller E, Backstrand KH, Silver B, Marcus KC, Tarbell NJ, Friedberg J, Canellos GP, Mauch PM (2002a) Long-term survival and competing causes of death in patients with early-stage Hodgkin's disease treated at age 50 or younger. J Clin Oncol 20: 2101 2108

Ng AK, Bernardo MVP, Weller E, Backstrand K, Silver B, Marcus KC, Tarbell NJ, Stevenson MA, Friedberg JW, Mauch PM (2002b) Second malignancy after Hodgkin disease treated with radiation therapy with or without chemotherapy: long-term risks and risk factors. Blood 100: $1989-1996$

Offit K, Gilad S, Paglin S, Kolachana P, Roisman LC, Nafa K, Yeugelewitz V, Gonzales M, Robson M, McDermott D, Pierce HH, Kauff ND, Einat P, Jhanwar S, Satagopan JM, Oddoux C, Ellis N, Skaliter R, Yahalom J (2002) Rare variants of ATM and risk for Hodgkin's disease and radiation-associated breast cancers. Clin Cancer Res 8(12): 3813-3819

Ramsey J, Birrell G, Lavin M (1996) Breast cancer and radiotherapy in ataxia-telangiectasia heterozygote. Lancet 347: 1627

Rosenberg SA, Kaplan HS (1985) The evolution and summary results of the Stanford randomized clinical trials of the management of Hodgkin's disease: 1962 -1984. Int J Radiat Oncol Biol Phys 11: 5-22

Sankila R, Garwicz S, Olsen JH, Dollner H, Hertz H, Kreuger A, Langmark F, Lanning M, Moller T, Tulinius H (1996) Risk of subsequent malignant neoplasms among 1,641 Hodgkin's disease patients diagnosed in childhood and adolescence: a population-based cohort study in the five Nordic countries. Association of the Nordic Cancer Registries and the Nordic Society of Pediatric Hematology and Oncology. J Clin Oncol 14: $1442-1446$

Santoro A, Bonadonna G, Bonfante V, Valagussa P (1982) Alternating drug combinations in the treatment of advanced Hodgkin's disease. $N$ Engl J Med 306: $750-770$

Sieber M, Engert A, Diehl V (2000) Treatment of Hodgkin's disease: results and current concepts of the German Hodgkin's Lymphoma Study Group. Ann Oncol 11(Suppl 1): $81-85$

Spaepen K, Stroobants S, Dupont P, Thomas J, Vandenberghe P, Balzarini J, De Wolfe-Peeters C, Mortelmans L, Verhoef G (2001) Can positron emission tomography with [(18)F]-fluorodeoxyglucose after first-line treatment distinguish Hodgkin's disease patients who need additional therapy from others in whom additional therapy would mean avoidable toxicity? Br J Haematol 115(2): $272-278$

Specht L, Gray RG, Clarke MJ, Peto R (1998) Influence of more extensive radiotherapy and adjuvant chemotherapy on long-term outcome of early-stage Hodgkin's disease: a meta-analysis of 23 randomized trials involving 3,888 patients. International Hodgkin's Disease Collaborative Group. J Clin Oncol 16: 830-843

Swerdlow AJ, Barber JA, Vaughan Hudson G, Cunningham D, Gupta RK, Hancock BW, Horwich A, Lister TA, Linch DC (2000) Risk of second malignancy after Hodgkin's disease in a collaborative British cohort: the relation to age at treatment. J Clin Oncol 18: 498-509

Tabar L, Yen M-F, Vitak B, Chen H-HT, Smith RA, Duffy SW (2003) Mammography service screening and mortality in breast cancer patients: 20-year follow-up before and after introduction or screening. Lancet 361: $1405-1410$

Tinger A, Wasserman TH, Klein EE, Miller EA, Roberts T, Piephoff JV, Kucik NA (1997) The incidence of breast cancer following mantle field radiation therapy as a function of dose and technique. Int J Radiat Oncol Biol Phys 37: $865-870$

Travis LB, Curtis RE, Boice Jr JD (1996) Late effects of treatment for childhood Hodgkin's disease. N Engl J Med 335: $352-353$

Travis LB, Gospodarowicz $M$, Curtis RE, Clarke EA, Andersson M, Glimelius B, Joensuu T, Lynch CF, van Leeuwen FE, Holowaty E, Storm 
H, Glimelius I, Pukkala E, Stovall M, Fraumeni Jr JF, Boice Jr JD, Gilbert E (2002) Lung cancer following chemotherapy and radiotherapy for Hodgkin's disease. J Natl Cancer Inst 94: $182-192$

Travis LB, Hill DA, Dores GM, Gospodarowicz M, van Leeuwen FE, Holowaty E, Glimelius B, Andersson $\mathrm{M}$, Wiklund $\mathrm{T}$, Lynch $\mathrm{CF}$ van't Veer MB, Glimelius I, Storm H, Pukkala E, Stovall M, Curtis R, Boice Jr JD, Gilbert E (2003) Breast cancer following radiotherapy and chemotherapy among young women with Hodgkin disease. JAMA 290: $465-475$

Tucker MA, Coleman CN, Cox RS, Varghese A, Rosenberg SA (1988) Risk of second cancers after treatment for Hodgkin's disease. N Engl J Med 318: $76-81$

United Nations Scientific Committee on the Effects of Atomic Radiation (1994) Sources and Effects of Ionizing Radiation: UNSCEAR 1994 Repor to the General Assembly with Scientific Annexes. New York NY: United Nations

van Leeuwen FE, Klokman WJ, Stovall M, Dahler EC, van't Veer MB, Noordijk EM, Crommelin MA, Aleman BM, Broeks A, Gospodarowicz M, Travis LB, Russell NS (2003) Roles of radiation dose, chemotherapy, and hormonal factors in breast cancer following Hodgkin's disease. J Natl Cancer Inst 95: 971-980

van Leeuwen FE, Klokman WJ, Veer MB, Hagenbeek A, Krol AD, Vetter UA, Schaapveld M, van Heerde P, Burgers JM, Somers R, Aleman BM (2000) Long-term risk of second malignancy in survivors of Hodgkin's disease treated during adolescence or young adulthood. J Clin Oncol 18: $487-497$

van Leeuwen FE, Swerdlow AJ, Valagussa P, Tucker MA (1999) Second cancers after treatment of Hodgkin's disease. In Hodgkin's Disease, Mauch PM, Armitage JO, Diehl V, Hoppe RT. and Weiss LM (eds) pp 607-632. Philadelphia: Lippincott, Williams \& Wilkins

Warren RM, Crawley A (2002) Is breast MRI ever useful in a mammographic screening programme? Clin Radiol 16: 536-544

Wolden SL, Lamborn KR, Cleary SF, Tate DJ, Donaldson SS (1998) Second cancers following pediatric Hodgkin's disease. J Clin Oncol 16: 536-544 Yahalom J, Petrek JA, Biddinger PW, Kessler S, Dershaw D, McCormick B, Osborne MP, Kinne DA, Rosen PP (1992) Breast cancer in patients irradiated for Hodgkin's disease: a clinical and pathologic analysis of 45 events in 37 patients. J Clin Oncol 10: 1674-1681 